\title{
Inhibition of tumor promoting signals by activation of SSTR2 and opioid receptors in human breast cancer cells
}

Geetanjali Kharmate, Padmesh S Rajput, Yu-Chen Lin and Ujendra Kumar

\begin{abstract}
Background: Somatostatin receptors (SSTRs) and opioid receptors (ORs) belong to the superfamily of G-protein coupled receptors and function as negative regulators of cell proliferation in breast cancer. In the present study, we determined the changes in SSTR subtype 2 (SSTR2) and $\mu, \delta$ and $\mathrm{k}$-ORs expression, signaling cascades and apoptosis in three different breast cancer cells namely MCF-7, MDA-MB231 and T47D.

Methods: Immunocytochemistry and western blot analysis were employed to study the colocalization and changes in MAPKs (ERK1/2 and p38), cell survival pathway (PI3K/AKT) and tumor suppressor proteins (PTEN and p53) in breast cancer cell lines. The nature of cell death upon activation of SSTR2 or OR was analysed using flow cytometry analysis.

Results: The activation of SSTR2 and ORs modulate MAPKs (ERK1/2 and p38) in cell dependent and possibly estrogen receptor (ER) dependent manner. The activation of tumor suppressor proteins phosphatase and tensin homolog (PTEN) and p53 antagonized the PI3K/AKT cell survival pathway. Flow cytometry analyses reveal increased necrosis as opposed to apoptosis in MCF-7 and T47D cells when compared to ER negative MDA-MB231 cells. Furthermore, receptor and agonist dependent expression of ORs in SSTR2 immunoprecipitate suggest that SSTR2 and ORs might interact as heterodimers and inhibit epidermal growth factor receptor phosphorylation.
\end{abstract}

Conclusion: Taken together, findings indicate a new role for SSTR2/ORs in modulation of signaling pathways involved in cancer progression and provide novel therapeutic approaches in breast cancer treatment.

Keywords: Breast cancer, Mitogen activated protein kinases, Opioid receptors and somatostatin receptor-2

\section{Background}

Somatostatin (SST) is a multifunctional growth hormone inhibitory neuropeptide, regulating different arrays of functions in the brain, endocrine and exocrine tissues. One of the prominent functions of SST is the negative regulation of cell proliferation in normal as well as pathological conditions including pituitary, pancreatic and breast tumors [1-5]. The anti-proliferative effects of SST occur indirectly through the inhibition of growth factors such as insulin growth factor-1 and epidermal growth factor and angiogenesis [6-9]. The direct antiproliferative effect of SST is by binding to seven transmembrane G-protein coupled receptors (GPCRs) namely

\footnotetext{
* Correspondence: ujkumar@mail.ubc.ca

Faculty of Pharmaceutical Sciences, The University of British Columbia, Vancouver, BC V6T1Z3, Canada
}

somatostatin receptors 1-5 (SSTR1-5). This direct effect of SST is either cytostatic (cell cycle arrest) or cytotoxic (apoptosis) [2,10-12]. SSTR1-5 subtypes are variably expressed in various human tumors including breast cancer tissues and cells $[4,12,13]$. We have previously shown a significant correlation between mRNA and protein expression of SSTRs with histological tumor markers as well as with expression levels of estrogen receptors (ER) and progesterone receptors [4]. These results indicate that the presence of hormone receptors might play crucial role on SSTR effectiveness in breast cancer.

SST and SSTRs are highly expressed in breast cancer cells as well as autopsied breast tissue. However, SSTR2 is the prominent receptor subtype expressed ubiquitously and abundantly in breast tumor tissues and 
cancer cells. Vikic-Topic et al., described that SSTR2 transcript is predominantly expressed in all breast tissue samples and followed by SSTR1, SSTR3 and SSTR4 [14]. Additionally, Pfeiffer et al., reported that SSTR2 and SSTR5 as the predominant subtypes expressed in primary breast tumors [15]. Moreover, MCF-7 cells with over-expression of SSTR2 display diminished rate of cell proliferation [16]. SSTR2 exerts its anti-proliferative effect by either activating or suppressing various signal transduction pathways including mitogen activated protein kinases (MAPK), phosphatidylinositol-3-protein kinase (PI3K)/AKT, phosphotyrosine phosphatases such as PTP1 and PTP2 [17-21]. The activation of multiple signaling pathways consequently leads to the induction of cell cycle arrest via activation of cyclin dependent kinase inhibitor $\left(\mathrm{p} 27^{\mathrm{Kip} 1}\right)$ as well as apoptosis. SSTRs positive tumors are less malignant with higher survival rate whereas the lack of SSTRs expression has also been associated with poorly differentiated and invasive tumor [22]. This could partly be attributed to the over-expression of epidermal growth factor receptors (EGFRs) in breast cancer that are associated with poor prognosis and patient survival rate $[13,23,24]$. Importantly, in MCF-7 cells, overexpression of SSTR2 resulted in suppression of EGFR expression [16]. Further in support, our recent studies have also described attenuation of EGFR phosphorylation and suppression of tumor promoting signals in breast cancer cells as well as in human embryonic kidney (HEK)293 cells transfected with SSTR1 or SSTR5 [13,20,21].

Like SSTRs, opioid receptor (ORs), namely $\mu, \delta$ and $\kappa$ are also the members of GPCR family. SSTRs and ORs share $>40 \%$ structural homology and are well expressed in various breast cancer cells as well as in solid breast tumor tissues [25,26]. ORs are well characterized for their analgesic role and like SSTRs have recently been reported as negative regulators of cell growth in various tumors including, prostrate, lung, kidneys and breast cancer [27-29]. It has been previously shown that $>50 \%$ of invasive ductal carcinomas are positive for opioid peptide like immunoreactivity [30]. Furthermore, human adrenocarcinoma and breast cancer cell lines exhibited the binding site for opioids. The opioid agonist $\left[\mathrm{D}^{-} \mathrm{Ala}^{2}\right.$, $\mathrm{D}^{-\mathrm{Leu}^{2}}{ }^{2}$ enkephalin (DADLE), displayed inhibition of cell proliferation in a concentration dependent manner and was reversed in the presence of antagonist naloxone $[29,31,32]$.

SSTR and OR subtypes constitute functional heteromeric complexes within same sub-family and other GPCRs and modulate receptor trafficking and signaling properties [25,33-37]. SSTR5 and dopamine receptor 2 (D2R) heterodimerization synergistically control the hyper-secretion of growth hormone and prolactin in pituitary adenomas [38,39]. These observations have led to the application of new chimeric molecules of D2R and SSTR5 for the treatment of pituitary tumor acromegaly [1,38-40]. Furthermore, SSTR2 interfere with PI3K signaling via disruption of the SSTR2/p85 subunit complex consequently inhibiting the cell proliferation and tumor growth [17]. HEK-293 cells co-transfected with SSTR2 and $\mu \mathrm{OR}$ constituted stable heterodimers thereby regulating the receptor phosphorylation, internalization and desensitization [15]. Whether SSTR2 functionally interacts with ORs in breast cancer cells expressing these receptors endogenously and function in similar manner as described in heterologous system is largely elusive. We hypothesize that the simultaneous activation of SSTR2 and ORs may exert pronounced antiproliferative effect via changes in signaling pathways in breast cancer cells. Multiple studies have documented that estrogen upregulated the expression of SSTR2 mRNA and protein via ER in T47D and ZR75-1 (ER + ve) breast cancer cells. These findings may anticipate the role of SSTR2 in ER responsiveness of breast cancer [41-43]. However, SSTR2 and OR subtypes mediated effect on signaling pathways in part are dependent on the presence of ER in breast cancer cells is still elusive. In the present study, we focus to determine the expression of SSTR2 and ORs and the changes in receptor expression and signaling pathways upon treatment with receptor specific agonist in human breast cancer cell lines; MCF-7 (ER + ve), MDA-MB231 (ER-ve), and T47D (ER + ve).

\section{Materials and methods \\ Chemicals and reagents}

SSTR2 specific non-peptide agonist L-779,976 was provided by Dr. Rohrer from Merck \& Co. Specific agonists for $\mu \mathrm{OR}$ (DAMGO), $\delta \mathrm{OR}$ ([D-Ala $\left.{ }^{2}\right]$ - Deltorphin II) and KOR ( \pm )-U-50488 hydrochloride) were purchased from Tocris Biosciences (Ellisville, MO). Polyclonal rabbit anti-SSTR2 antibody was developed in our laboratory $[44,45]$. The antibodies against ORs $(\mu, \delta$ and $\kappa)$, phosphorylated and total-EGFR were obtained from Santa Cruz Biotechnology (Santa Cruz, CA). Rabbit polyclonal antibodies against phosphorylated and total-ERK1/2, p38, PI3K, AKT, PTEN and p53 were purchased from Cell Signaling Technology (Mississauga, ON). Goat antirabbit or donkey anti-goat Alexa Fluor-488 and Alexa Fluor-594 were purchased from Invitrogen (Burlington, $\mathrm{ON})$. Annexin-APC V was obtained from BD Biosciences (Mississauga, ON). All experiments were performed in compliance with Office of Research and Biosafety Committee guidelines at the University of British Columbia.

\section{Cell lines and culture}

Human breast cancer cell lines, MCF-7 and T47D (ER + ve) were maintained in RPMI 1640 medium supplemented with $10 \%(\mathrm{v} / \mathrm{v})$ fetal bovine serum (FBS) and 1\% antibiotic (penicillin/streptomycin) at $37^{\circ} \mathrm{C}, 5 \% \mathrm{CO}_{2}$ as previously described [4,13]. MDA-MB231 (ER-ve) cells were maintained 
in Leibovitz's L-15 medium supplemented with $10 \%(\mathrm{v} / \mathrm{v})$ FBS and $1 \%$ antibiotic (penicillin/streptomycin) at $37^{\circ} \mathrm{C}$ in a $\mathrm{CO}_{2}$ free atmosphere.

\section{Indirect immunofluorescence immunocytochemistry}

Breast cancer cells were processed for indirect immunofluorescence immunocytochemistry as described earlier $[13,21]$. Briefly, cells were washed and fixed with $4 \%$ paraformaldehyde and followed by treatment with Triton X-100 for $10 \mathrm{~min}$ at room temperature. The cells were incubated with anti-goat $\mu, \delta$, and $\mathrm{k}-\mathrm{OR}(1: 300)$ primary antibodies overnight at $4{ }^{\circ} \mathrm{C}$ and followed by incubation in goat-anti-rabbit Alexa 488 (1:700) conjugated secondary antibodies for $1 \mathrm{~h}$ at room temperature for final color development. The cells were viewed and photographed on a Leica DMLB microscope attached to a Retiga 2000R camera. The specificity of immunoreactivity was determined in absence of primary antibodies or in presence of preimmune serum as described earlier [45].

\section{Western blot analyses}

Membrane extracts as well as whole cell lysate prepared from control and treated cells were fractionated on SDSPAGE as described previously $[13,21]$. To determine the receptor expression in membrane extracts, blots were incubated with primary antibodies against SSTR2 (1:400) and $\mu, \delta$ and $\kappa-O R$ (1:500). The status of signaling molecules were examined by incubating the immunoblots with antibodies against phosphorylated and/or total extracellular regulated protein kinase 1/2 (ERK1/2), p38, PI3K, AKT, PTEN and p53 (1:1000). Membrane was incubated with peroxidase conjugated secondary antibodies respectively. The bands were detected using chemiluminescence in accordance to the manufacturer's instructions (Amersham Biosciences). Images were captured using the Alpha Innotech FluorChem 8800 gel box imager and FluorChem software was used to quantify the blots. Tubulin was used as the loading control.

\section{Co-Immunoprecipitation (Co-IP)}

Breast cancer cells were treated with specific agonists for SSTR2, L-779,976 (10 nM) and $\mu$ OR (DAMGO; $1 \mu \mathrm{M}$ ), SOR (Deltorphin-II; $1 \mu \mathrm{M})$, or $\kappa \mathrm{OR}(\mathrm{U} 50488 \mathrm{HCl} ; 1 \mu \mathrm{M})$ alone or in combination for $15 \mathrm{~min}$ at $37^{\circ} \mathrm{C} .200 \mu \mathrm{g}$ of total membrane protein was solubilized in $1 \mathrm{ml}$ of radioimmune precipitation assay (RIPA) buffer $(150 \mathrm{mM} \mathrm{NaCl}$, $50 \mathrm{mM}$ Tris- $\mathrm{HCl}, 1 \%$ Nonidet P-40, 0.1\% SDS, $0.5 \%$ sodium deoxycholate, $\mathrm{pH}$ 8.0) for $1 \mathrm{~h}$ at $4^{\circ} \mathrm{C}$ as described earlier [20,21]. Samples were incubated with anti-SSTR2 antibody (1:200) for immunoprecipitation and purified with protein A/G-agarose beads overnight at $4^{\circ} \mathrm{C}$. Purified proteins were subjected to $7 \%$ SDS-PAGE and probed for the expression of ORS using anti- $\mu, \delta$ and $\mathrm{k}-\mathrm{OR}$ antibodies (1:500) respectively as described previously [20,21].

\section{Flow cytometry analysis for apoptosis/necrosis}

Cells were harvested and treated with L-779,976, DAMGO, Deltorphin-II, or U50488 $\mathrm{HCl}$ alone and/or in combination for $30 \mathrm{~min}$ at $37^{\circ} \mathrm{C}$. Annexin V-APC staining was performed according to the manufacturer's protocol (BD Biosciences). Cells were washed twice with cold PBS and resuspended in $1 \mathrm{X}$ binding buffer $(0.1 \mathrm{M}$ Hepes, $\mathrm{pH} 7.4,1.4 \mathrm{M} \mathrm{NaCl}, 25 \mathrm{mM} \mathrm{CaCl}_{2}$ ) at a cell density of $1 \times 10^{5} \mathrm{cells} / \mathrm{ml}$. Annexin V-APC and propidium iodide were added to the cell suspension for $15 \mathrm{~min}$. Prior to flow cytometry, $400 \mu \mathrm{l}$ of $1 \mathrm{X}$ binding buffer was added and cells were analyzed using FACS Calibur flow cytometer (Becton Dickinson, San Jose, CA). A minimum of 10,000 events were recorded for each sample. Cells positive for Annexin V-APC were identified as apoptotic whereas cells positive for both Annexin V-APC and propidium iodide were characterized as necrotic.

\section{Statistical analysis}

The changes in the expression of proteins were quantified using ANOVA and post hoc Dunnett's or Bonferroni's tests. Statistical analysis was performed using GraphPad Prism 4.0 to determine the significant changes. Significant statistical differences were taken at $* p<0.05$. Results are presented as mean \pm SEM from three independent experiments $(n=3)$.

\section{Results}

\section{Comparative distribution of SSTR2 and ORs in MCF-7, MDA-MB231 and T47D cells}

SSTR2 and ORs expression at the cellular levels and in membrane fractions was accomplished by immunofluorescence immunocytochemistry and western blot analysis respectively. MCF-7 cells, displayed strong membrane expression of SSTR2 and $\mu, \delta, \mathrm{K}-\mathrm{ORs}$ whereas intracellular expression of SSTR2 was weak than the ORs (Figure 1A). In MDA-MB231 cells, SSTR2 and $\mu, \delta$ and $\kappa-O R s$ like immunoreactivity was observed at the cell surface with a dominant expression of $\delta$ and $\kappa \mathrm{OR}$, whereas, the receptors expression in the cytoplasmic compartment was comparable (Figure 1A). In contrast, T47D cells displayed strong expression of SSTR2 and $\mu, \delta, \kappa-O R s$ at the cell surface as well as intracellularly (Figure 1A).

To support the cellular distribution by immunocytochemistry receptor like immunoreactivity was also confirmed using Western blot analysis. As shown in Figure 1B, SSTR2 was well expressed at the expected molecular size of $\sim 57 \mathrm{kDa}$ with relatively higher expression in MDAMB231 cells in comparison to MCF-7 and T47D. The expression level of SSTR2 was comparatively less in T47D cells than MCF-7 and MDA-MB231 cells. In contrast, $\mu \mathrm{OR}$ $(\sim 50 \mathrm{kDa})$ and $\mathrm{kOR}(\sim 46 \mathrm{kDa})$ were well expressed in MCF-7 cells. Conversely, the expression of $\mathrm{kOR}$ in membrane extract prepared from MDA-MB231 and T47D cells 

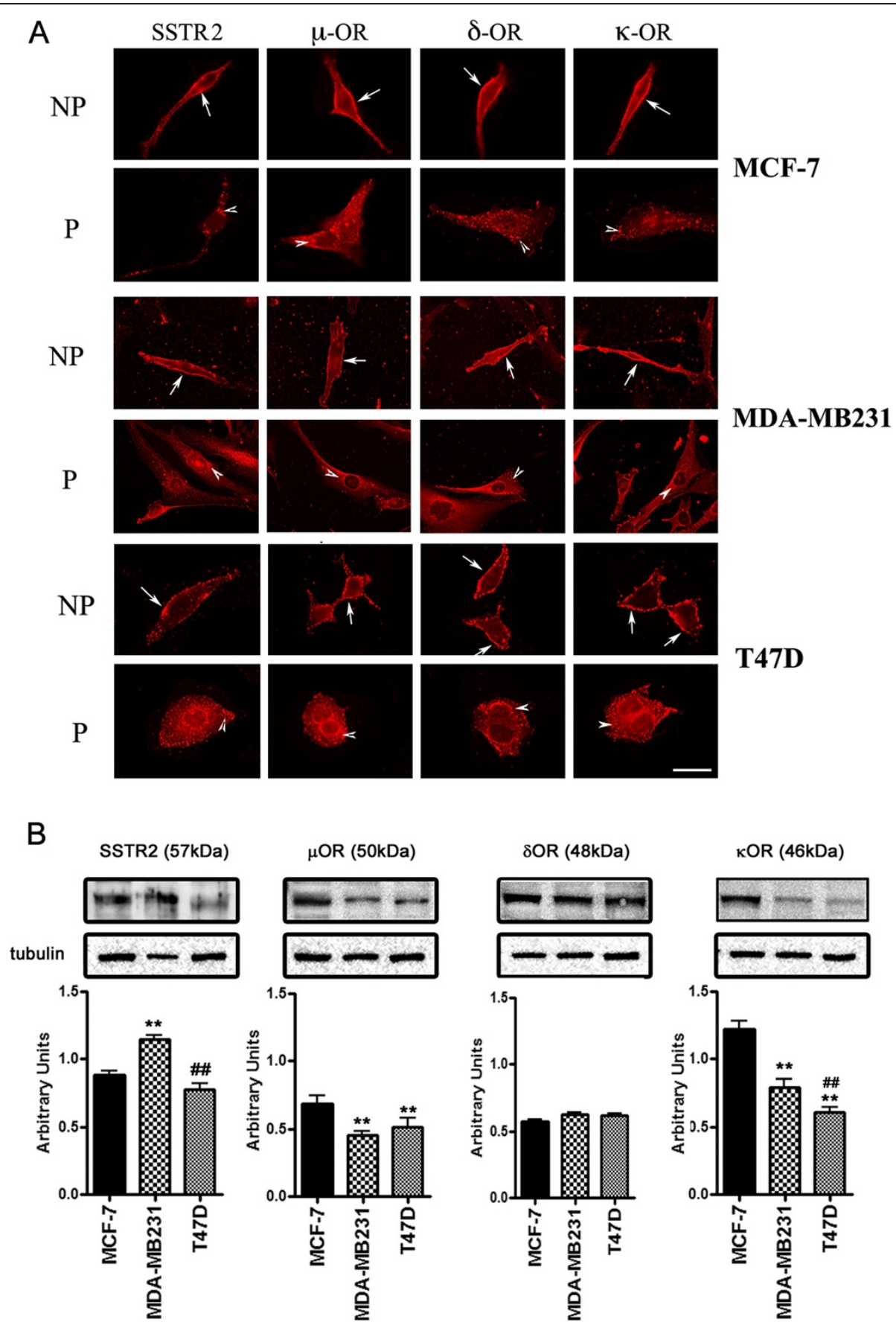

Figure 1 Differential expression of SSTR2 and $\mu, \delta, \mathbf{k}$-ORs in human breast cancer cells. (A) Indirect immunofluorescence staining showing membrane (non-permeabilized, NP) and intracellular (permeabilized, $\mathbf{P}$ ) expression of SSTR2 and $\mu, \delta, \mathrm{K}$-ORs in breast cancer cells. In the representative panels receptor expression at the cell surface is indicated by arrows whereas arrowheads indicate intracellular expression.

(B) Cell membrane extracts obtained from MCF-7, MDA-MB231 and T47D breast cancer cells were subjected to Western blot analysis and probed with specific primary antibodies to detect the receptor expression. The immunoblots show differential expression of SSTR2 ( 57 kDa) and $\mu$ ( $50 \mathrm{kDa}), \delta(\sim 48 \mathrm{kDa}), \mathrm{K}(\sim 46 \mathrm{kDa})-\mathrm{ORs}$ in a cell specific manner. Histogram represents densitometric analysis of the receptor expression normalized by using tubulin as loading control. Results are expressed as mean \pm SEM $(n=3) .{ }^{* *} \boldsymbol{p}<\mathbf{0 . 0 1}$, MCF-7 vs. MDA-MB231 or T47D cells; $\#$ \# $<$ 0.01; MDA-MB231 vs. T47D. Scale bar $10 \mu \mathrm{m}$. 
was relatively weak (Figure $1 \mathrm{~B})$. The expression of $\delta \mathrm{OR}$ $(\sim 48 \mathrm{kDa})$ was comparable in all three cell lines. These observations indicate cells-specific expression of SSTR2 and ORs.

SSTR2 and ORs modulate MAPKs in a cell-specific manner We next determined whether receptor activation regulate MAPKs (ERK1/2 and p38) in breast cancer cells. In MCF-7 cells, L-779,976, DAMGO and Deltorphin-II alone inhibit the phosphorylation of ERK1/2 (p-ERK1/2) (Figure 2A). Furthermore, L-779,976 in the presence of DAMGO or Deltorphin-II displayed p-ERK1/2 comparable to control. In contrast, U50488HCL, alone or in combination with L-779,976 significantly elevated pERK1/2 in MCF-7 cells (Figure 2A). In MDA-MB231 cells, L-779,976 alone had no significant effect on pERK1/2. DAMGO alone induced p-ERK1/2 whereas in combined treatment with L-779,976 decreased p-ERK1/2. In contrast, Deltorphin-II alone had no significant effect on p-ERK1/2 whereas in combination with L-779,976 enhanced the levels of p-ERK1/2 in MDA-MB231 cells (Figure 2A). Furthermore, in MDA-MB231 cells the activation of $\mathrm{KOR}$ enhanced $\mathrm{p}$-ERK $1 / 2$ which was significantly decreased to the control level upon combined treatment with SSTR2 agonist L-779,976. In T47D cells, L-779,976 maintained p-ERK1/2 comparable to control. The activation of $\mu \mathrm{OR}$ displayed comparable $\mathrm{p}$-ERK1/2 but significantly increased in combination with L-779,976. The status of p-ERK1/2 was not changed upon activation of SOR alone whereas expression level was diminished significantly in presence of L-779,976 and Deltorphin-II. Activation of $\mathrm{KOR}$ alone had no effect on p-ERK1/2 however simultaneous activation of SSTR2/KOR inhibited pERK1/2 when compared to control (Figure 2B).

In addition to ERK1/2, in tumor cells, p38 is a crucial mediator of apoptosis, cell-cycle arrest, cell differentiation and tumor suppression [46,47]. The pro- and/or anti-apoptotic role of p38 is attributed to the cell-type and stimuli. Of note, p38 phosphorylation remained comparable to control in MCF-7 cells upon treatments with SSTR2 and ORs agonists alone or in combination (Figure 2B). Unlike MCF-7 cells, the p-p38 was not detected in MDA-MB231 and T47D cells across all indicated treatments. Collectively, these data suggest that basal expression of p-p38 is relatively higher in MCF-7 cell in comparison to MDA-MB231 or T47D cells without any discernible changes upon SSTR2 and ORs activation.
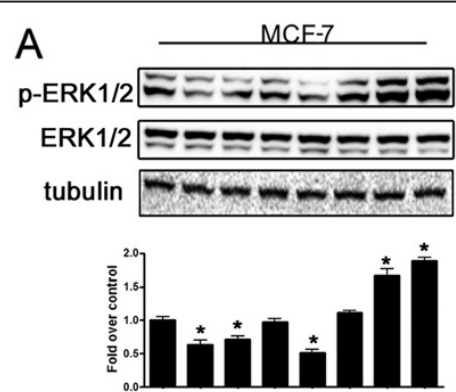

B
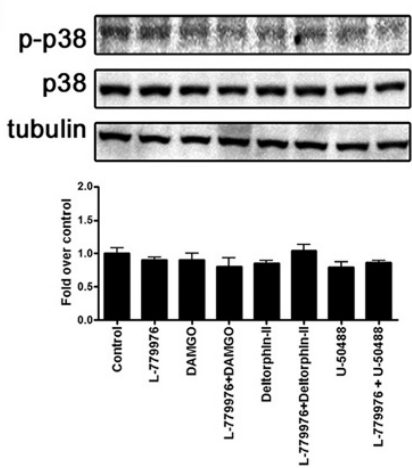

MDA-MB231
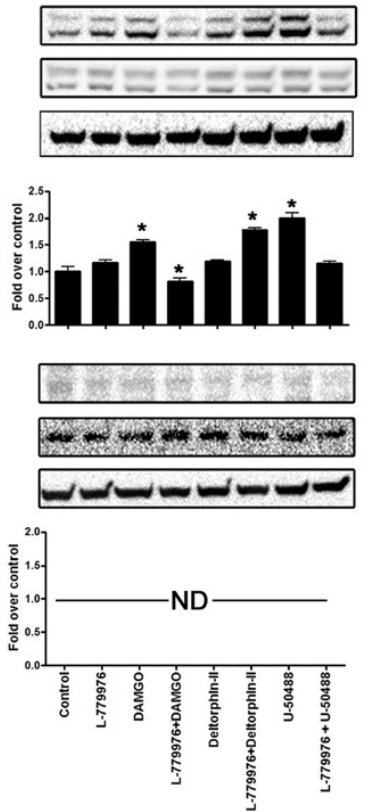
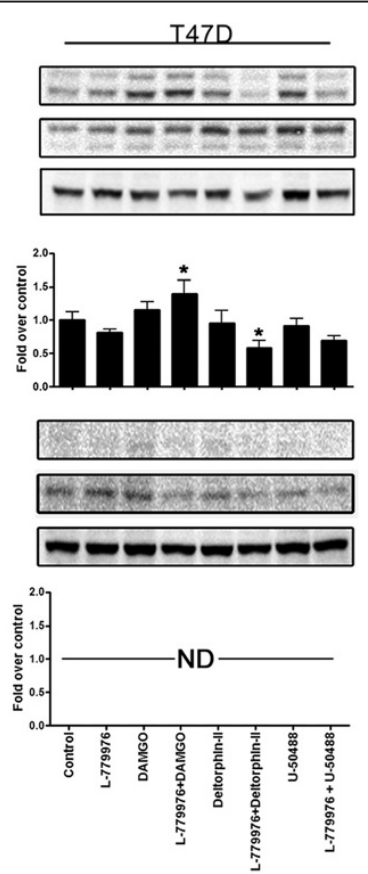

Figure 2 MAPKs (ERK1/2 and p38) are modulated in a receptor and cell-specific manner. Whole cell lysates obtained from MCF-7, MDA-MB231 and T47D cells following treatment with SSTR2 and ORs agonists alone and/or in combination were subjected to western blot analysis and probed for phospho-and total ERK1/2 and p38 (1:1000). (A) Immunoblots illustrating agonist mediated changes in phosphorylated ERK1/2 in cell-specific manner. (B) Immunoblots displaying changes in the phosphorylation of p38 upon specific agonist treatments in breast cancer cells. SSTR2 and ORs activation inhibited p38 phosphorylation upon indicated treatment. Histograms depict changes in the expression levels of ERK1/2 using densitometric analysis. The data presented here is a representation mean \pm SEM of three independent experiments. Significant difference was considered at ${ }^{*} \boldsymbol{p}<0.05$ vs. control. 
SSTR2 and ORs maintained basal activation of PI3K/AKT The aberrant activation and/or mutations in PI3K are associated with tumor growth and failure of hormonal therapy [48-50]. Accordingly, we next determined the status of phosphorylated PI3K/AKT in control and cells treated with SSTR2 and ORs specific agonists. No significant changes in the status of PI3K phosphorylation was observed in all cell lines upon indicated treatments, albeit lower levels of p-PI3K when compared to control (Figure 3A). Furthermore, irrespective to treatment and cell lines the status of AKT phosphorylation was without any significant changes across all treatments in all three breast cancer cells as indicated (Figure 3A).

\section{SSTR2 and ORs modulate tumor suppressor proteins PTEN and p53 in cell dependent manner}

Tumor suppressor proteins, PTEN and p53 serve as negative regulators of cell proliferation in breast cancer and mutations in PTEN and p53 are often associated with the activation of AKT cell survival pathway [49]. In MCF-7 cells, L-779,976 alone significantly enhanced the phosphorylation of PTEN whereas DAMGO alone or in combination with L-779,976 had no effect on p-PTEN (Figure 4A). Upon treatment with Deltorphin-II alone MCF-7 cells displayed elevated p-PTEN however co- activation of SSTR2 and $\delta \mathrm{OR}$ resulted in significant inhibition of p-PTEN comparable to control. Furthermore, in presence of $\mathrm{U} 50488 \mathrm{HCl}$ alone or in combination with L-779,976 the status of p-PTEN was without any significant effect in MCF-7 cells (Figure 4A). Conversely, in MDA-MB231 cells there was no discernible change in pPTEN across all the treatments as indicated. In T47D cells, L-779,976 alone and in combination with DAMGO significantly increased p-PTEN whereas DAMGO alone enhanced PTEN phosphorylation insignificantly different than the control. Furthermore, Deltorphin-II alone and in combination with L-779,976 displayed significant increase in the p-PTEN. In T47D cells, kOR agonist resulted in significant activation of PTEN whereas such effect was not significantly different from control upon synergistic activation of SSTR2 and kOR (Figure 4A).

As shown in Figure 4A, MCF-7 displayed no discernible changes in the expression of p53 across all the treatments. In contrast, in MDA-MB231 cells, L-779,976 alone was without any effect on p53 expression. DAMGO alone enhanced the expression of p53 significantly whereas in combination with L-779,976, p53 level was similar to the control. Deltorphin-II alone and in combination with L-799,796 significantly elevated the levels of p53. Furthermore, p53 expression was unchanged upon activation of
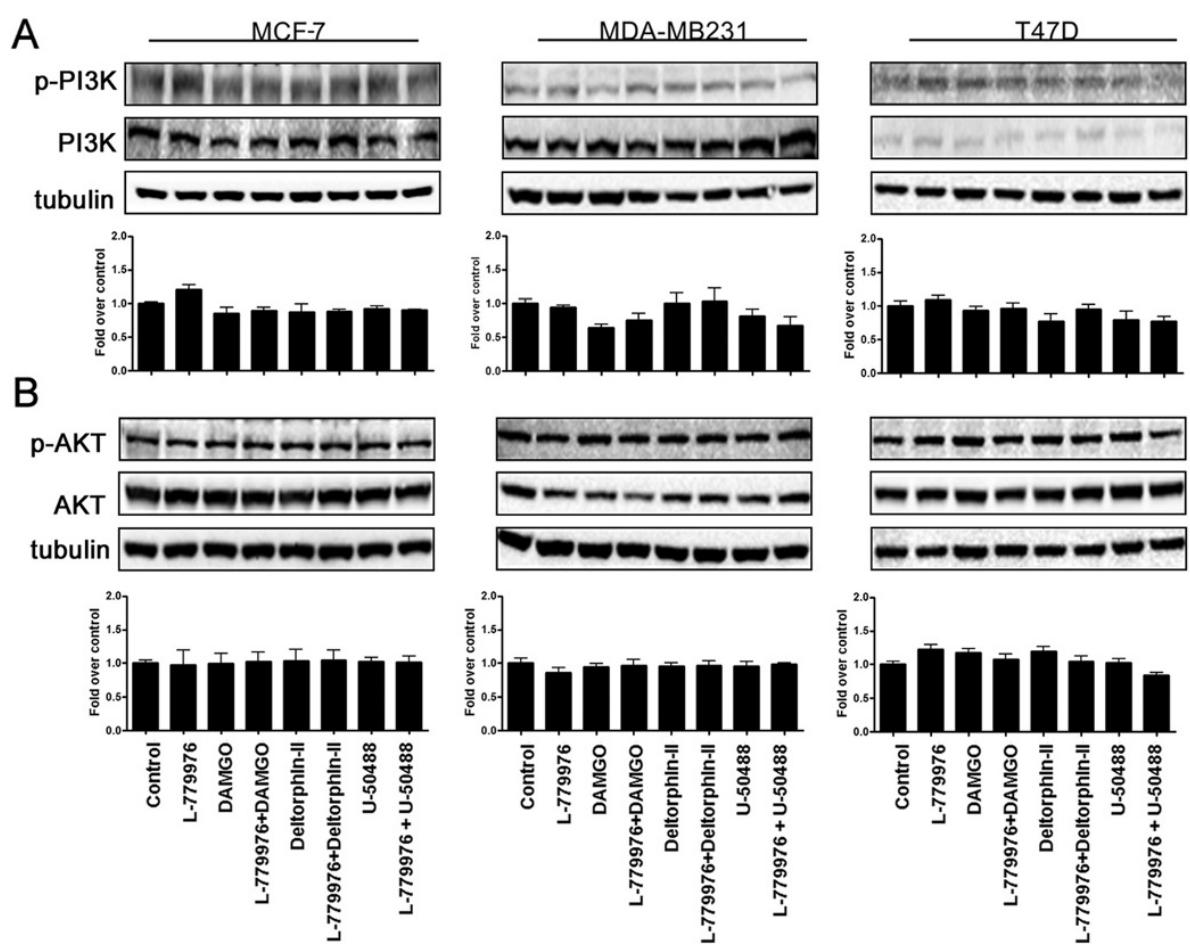

Figure 3 Activation of SSTR2 and ORs modulate PI3K/AKT cell survival pathway. Representative western blots illustrating the changes in the expression of PI3K (A) and AKT (B) in MCF-7, MDA-MB231 and T47D cells. Activation of SSTR2 and ORs individually or simultaneously exhibited no discernible changes in phosphorylation of PI3K and AKT, thus maintaining the status of PI3K AKT at control levels. Bar graphs represent the densitometric analysis of PI3K/AKT expression in different tumor cells. The data presented are a representation of triplicate experiments. 


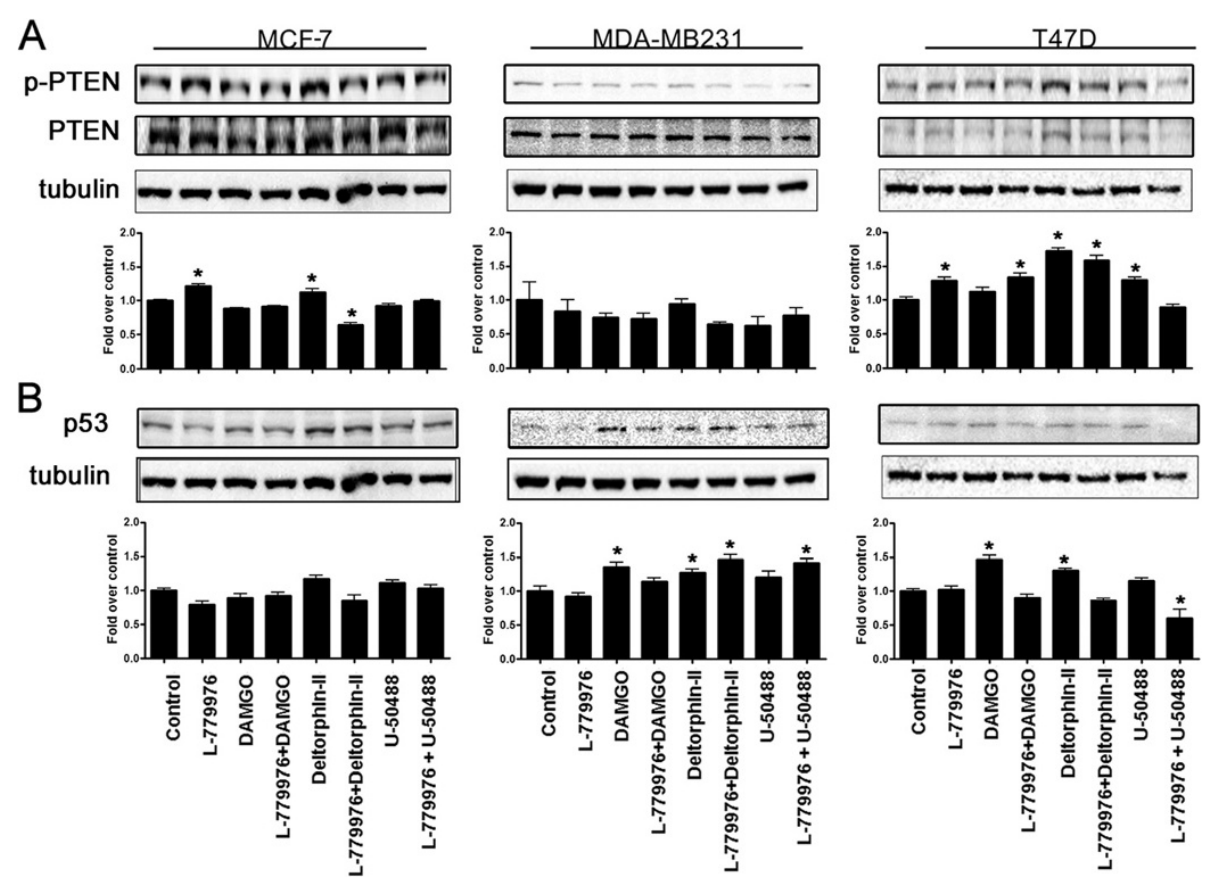

Figure 4 Tumor suppressor proteins PTEN and p53 are modulated in cell and receptor specific manner in tumor cells. Representative immunoblots showing the effect of SSTR2 or ORs activation on the expression of PTEN (A) and p53 (B) in MCF-7, MDA-MB231 and T47D cells respectively. (A) The expression of PTEN is enhanced in MCF-7 as well as T47D cells; however the MDA-MB231 cells displayed no discernible changes in the levels of PTEN. (B) The expression of p53 was in a receptor and cell-specific manner. Note the comparable changes in PTEN and p53 expression in MCF-7 and T47D cells. Histograms illustrate densitometric analysis of PTEN and p53 levels using tubulin as the loading control. The results presented here are representation of mean $\pm \mathrm{SEM}, n=3$. Significant difference was considered at ${ }^{*} \boldsymbol{p}<\mathbf{0 . 0 5}$ vs. control.

KOR alone whereas the combined treatment displayed significant increase in p53 expression in MDA-MB231 cells (Figure 4B). In T47D cells, L-779,976 alone and in combination with either DAMGO or Deltorphin-II exhibited no change in p53 expression. In contrast, DAMGO and Deltorphin-II alone significantly enhanced the p53 expression in comparison to the control. U50488 HCl alone did not affect p53 expression however, in combination with L-779,976, the p53 levels significantly decreased (Figure 4B). Taken together these observations suggest that SSTR2 and ORs upregulated the PTEN and p53 expression in a receptor and cell dependent manner.

SSTR2 and ORs induced early apoptosis and predominant cytostatic effect in cell dependent manner

The anti-proliferative effect of SSTR2 is mediated via two different mechanisms; cytostatic and cytotoxic. Accordingly, applying flow cytometry, we investigated the cellular response upon receptor specific agonist treatments. The results indicated apoptotic (9.05\%) and necrotic (19\%) cells in control MCF-7 cells whereas upon single treatment with L-779,976 number of the cells displaying apoptosis and necrosis was enhanced $(14.5 \%$ and $23.4 \%$ respectively) (Figure 5A). In presence of DAMGO alone or with L-779,976 cells displayed higher extent of necrosis $(25 \%$ and $27.8 \%$ respectively) without any significant changes in apoptosis (11.8\% and 12\%). Furthermore, the number of cells displaying apoptosis and necrosis was enhanced upon combined treatment with L-779,976 and Deltorphin-II (12\% and 26.7\%) than Deltorphin-II alone (9 and 23.6\%, respectively). In contrast, the activation of $\mathrm{kOR}$ with $\mathrm{U} 50488 \mathrm{HCl}$ alone caused higher necrosis (29.9\%), but was decreased to $23.4 \%$ upon combined treatment with L-779,976 whereas cells entering apoptosis was limited to $\sim 10 \%$ (Figure 5A).

As illustrated in Figure 5B, MDA-MB231 cells upon treatments with SSTR2 or $\mu, \delta$ and $\kappa$-ORs agonists alone or in combination displayed $<4 \%$ of apoptotic cell population. Conversely, cells undergoing necrosis increased (12.4\%) upon treatment with L-779,976 alone in comparison to the control (10.8\%). DAMGO alone enhanced the necrotic cells $(13.5 \%)$ whereas upon combined treatment with L-779,976, the number of cells going through necrosis were enhanced to $15.3 \%$ in MDA-MB231 cells (Figure 5B). Deltorphin-II alone enhanced the necrosis to $16 \%$; however, combined treatment with L-779,976 decreased necrosis to $12.9 \%$, similar to that seen with L-779,976 alone (12.4\%). Similarly, treatment with U50488 HCl led to $14.7 \%$ necrosis and was decreased to $11.6 \%$ upon combined treatment with L-779,976 (Figure 5B).

In basal condition T47D cells number of the cells going through apoptosis and necrosis cells were 3.65\% 


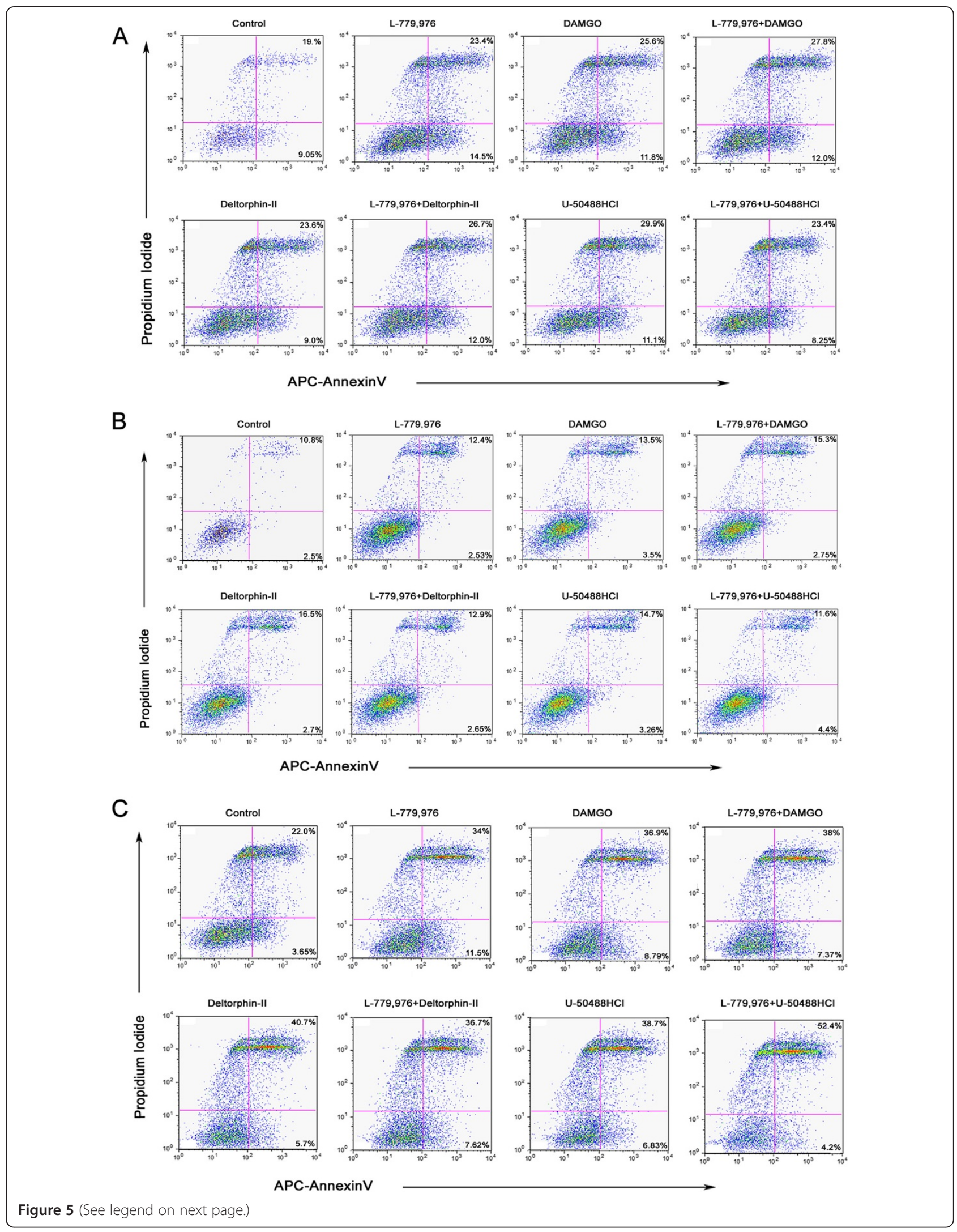


and $22 \%$ respectively (Figure $5 \mathrm{C}$ ). The treatment with L779,976 enhanced the apoptosis (11.5\%), however necrosis was elevated (34\%) when compared to the control. Interestingly, upon treatments with DAMGO, alone or in combination with L-779,976, the population of necrotic cells (36.9\% and 38\%) was enhanced significantly as compared to the early apoptotic cells $(8.79 \%$ and $7.37 \%)$. Deltorphin-II alone or in combination with L-779,976 displayed higher necrosis (40.7\% and 36.7\%) than apoptosis $(5.7 \%$ and $7.62 \%$ ) (Figure $5 \mathrm{C}$ ). Of note, combined treatment of $\mathrm{U} 50488 \mathrm{HCl}$ and L-779,976 markedly increased the necrosis (52.4\%) whereas exhibited only $4.2 \%$ apoptosis (Figure $5 \mathrm{C}$ ). These data indicate that ER + ve cells (MCF-7 and T47D) are more susceptible to necrosis upon simultaneous activation of SSTR2 and ORs than ER-ve cells (MDA-MB231).

\section{Expression of ORs in SSTR2 immunoprecipitate is cell and receptor-specific in tumor cells}

Previous studies using HEK-293 cells have demonstrated that ORs and SSTR2 constituted functional heterodimers with enhanced signaling properties [15]. To decipher the underlying mechanism by which SSTR2/ORs functionally interact in tumor cells expressing these receptors endogenously, SSTR2 immunoprecipitate was processed for the ex-

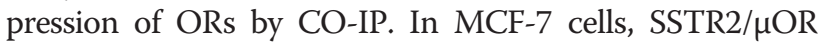
exists in a heteromeric complex at the expected molecular size of $\sim 120 \mathrm{kDa}$ in control as well as upon activation of both receptors independently (Figure 6A). However, with combined treatment of L-779,976 + DAMGO, there was significant loss in SSTR2/ $\mu$ OR complex (Figure 6A). In MDA-MB231 cells, complex formation of SSTR2/ $\mu \mathrm{OR}$ was weak in basal state. The SSTR2/ $\mu$ OR complex was enhanced significantly upon activation of SSTR2 and the receptor heterodimerization was lost upon treatments with DAMGO alone or in combination with L-779,876 (Figure 6A). SSTR2 immunoprecipitate prepared from control T47D cells was devoid of $\mu \mathrm{OR}$ expression. However, upon treatments with L-779,876 or DAMGO alone or in combination, SSTR2 immunoprecipitate displayed $\mu \mathrm{OR}$ expression at the expected size of $\sim 120 \mathrm{kDa}$ (Figure 6A).

In comparison to control, the heterodimerization between SSTR2/8OR strengthened upon treatments with specific agonists in MCF-7 cells (Figure 6B). In contrast, MDA-MB231 cells in basal condition displayed strong SSTR2/8OR complex formation and led to the dissociation upon agonists treatment (Figure 6B). In T47D cells, no interaction between SSTR2/8OR in basal as well as upon treatment with L-779,976 was seen. However, upon treatments with Deltorphin-II alone or in combination with L-779,976, cells exhibited significant expression of $\delta$ OR in SSTR2 immunoprecipitate.

SSTR2 immunoprecipitate prepared from control and $\mathrm{U} 50488 \mathrm{HCl}$ treated MCF-7 cells were devoid of KOR expression (Figure $6 \mathrm{C}$ ). Whereas cells treated with specific agonists for SSTR2 alone or in combination with $\mathrm{kOR}$ induced the complex formation between SSTR2/KOR (Figure 6C). In MDA-MB231 cells, activation of SSTR2 alone displayed increased complex formation between SSTR2/KOR however, upon treatments with $\mathrm{U} 50488 \mathrm{HCl}$ alone or in combination with L-779,976; the expression of KOR in SSTR2 immunoprecipitate was comparable to control (Figure 6C). Conversely, T47D cells, exhibited comparable expression of $\mathrm{KOR}$ in SSTR2 immunoprecipitate in control as well as upon treatment with SSTR2 agonist. However in comparison SSTR2/KOR complex formation increased upon treatment with $\mathrm{KOR}$ agonist alone and in combination with SSTR2 agonist (Figure 6C). These results strengthen the concept of ligand, cell dependency in possible heterodimerization between SSTR2 and ORs respectively. The specificity of immunoreactivity was confirmed in absence of primary antibodies and incubation with secondary antibodies alone as previously described $[20,21]$.

\section{EGFR phosphorylation in breast cancer cells is abolished in presence of synergistic activation of SSTR2 and ORs}

The observations that breast tumor progression associated with EGFR over-expression, phosphorylation and homoand/or heterodimerization suggested a crucial role of EGFR in breast cancer $[13,20,21,51]$. In order to identify the possible link between EGFR and SSTR2/ORs we determined the effect of SSTR2 and ORs activation on EGFR phosphorylation. In MCF-7 cells, SSTR2 agonist L-779 ,976 alone or in combination with ORs agonists decreased the phosphorylation of EGFR although not significantly different than the control (Figure 6D). Interestingly, MDA-MB231 and T47D cells displayed no EGFR phosphorylation across all treatments (Figure 6D). These data indicate that SSTR2 and ORs together maintained EGFR phosphorylation comparable to control in MCF-7 cells. The inhibition of EGFR phosphorylation is crucial in breast cancer, however, whether the changes seen in the downstream signaling pathways are in-part due to the lack of EGFR phosphorylation needs further investigation. 


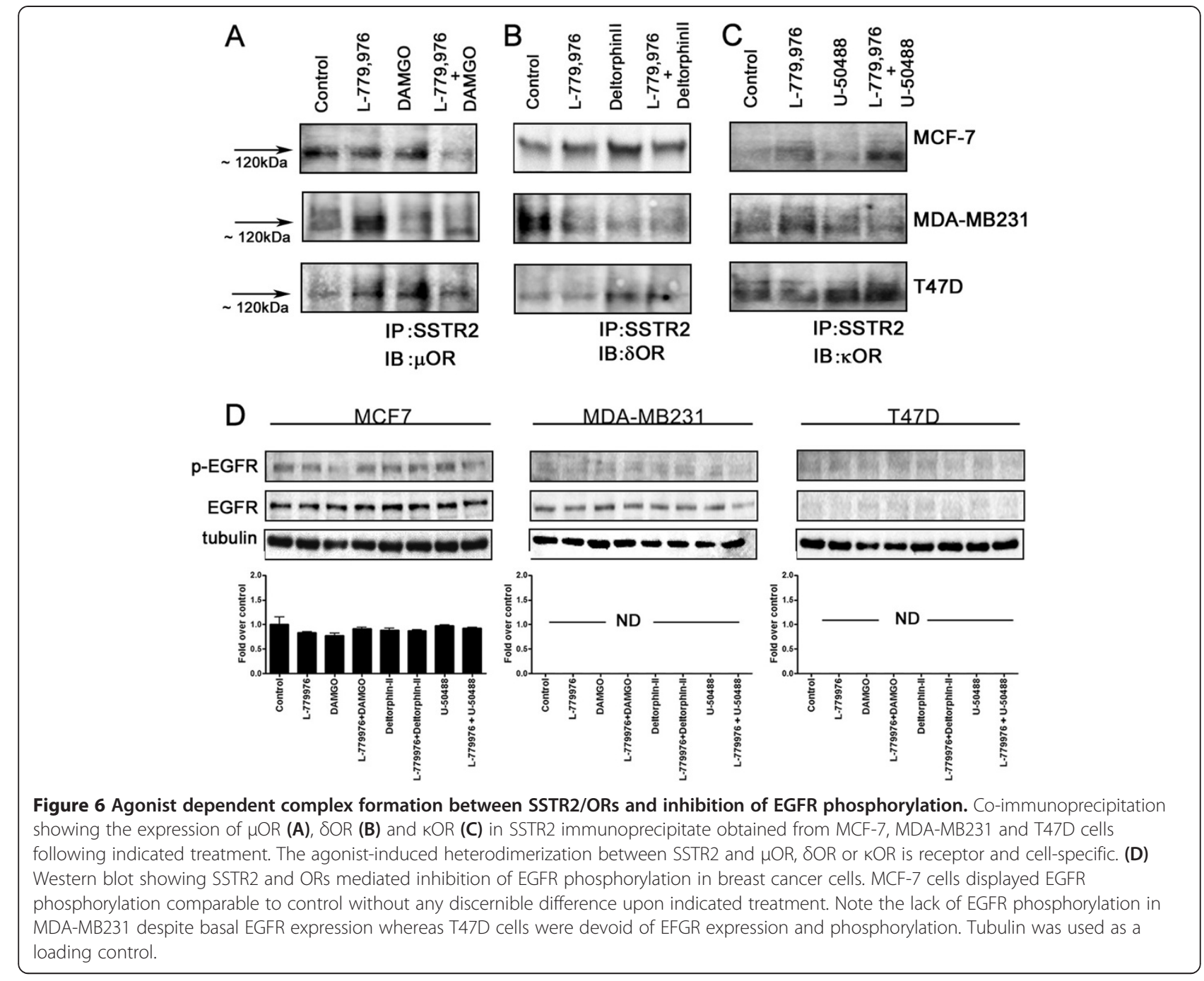

\section{Discussion}

In the present study we unfold the effects of activation of SSTR2 and ORs alone or in combination on signaling cascades and cell proliferation in human breast cancer cells including MCF-7, MDA-MB231 and T47D. The activation of SSTR2 and ORs modulate the MAPK pathway and inhibit the cell survival PI3K/AKT signaling molecules and thereby enhancing the expression of tumor suppressor proteins PTEN/p53 in cell and possibly ER dependent manner. These changes in modulation of downstream signaling were corroborated using flow cytometry describing the nature of cell death which showed eminent necrosis indicating the anti-proliferative effect of SSTR2 and ORs in breast cancer cells. In addition, our results describe receptor and agonist dependent expression of ORs in SSTR2 immunoprecipitate suggesting that SSTR2 and ORs might interact as heterodimers. In tumor cells, activation of SSTR2 and ORs inhibit the phosphorylation of EGFR. Although, there is growing understanding for the synergistic effect of many GPCRs in cells transfected with one or more receptor, this is the first comprehensive description of SSTR2 and ORs in tumor cells expressing both receptor subtypes endogenously. Our results demonstrate agonist dependent internalization of SSTR2 and ORs in receptor and cell-specific manner. The activation of SSTR2 and ORs modulate MAPKs (ERK1/2 and p38) and the expression of tumor suppressor proteins, PTEN and p53 resulting in the suppression of PI3K/AKT pathway. We further correlated the effects of SSTR2/ORs mediated signaling with the functional consequences by measuring the apoptosis and necrosis using flow cytometry. The results described here also revealed heterodimerization between SSTR2/OR and inhibition of EGFR phosphorylation. Our findings for the first time highlight the molecular mechanisms for the role of SSTR2 and ORs mediated antagonism of tumorigenic signaling pathways in human breast cancer cells in receptor dependent manner.

The co-expression of given receptors is a pre-requisite for heterodimerization and this was further supported by expression of ORs in SSTR2 immunoprecipitate. 
Consistent with previous studies in heterologous system, our results showed that SSTR2 exist as pre-formed heterodimers with $\mu, \delta$ and $\mathrm{k}$-ORs in breast cancer cells in receptor and cell-specific manner [15]. Moreover, SSTR2 formed heterodimers with $\delta$ and $\mathrm{KORs}$ in agonist and cell specific manner. Our results strengthen the concept that the activation of one receptor is capable of inducing receptor complex formation while second protomer may either stabilize or dissociate the heteromeric complex.

There is preponderance of evidence suggesting the mechanistic significance of GPCRs expression, trafficking and heterodimerization in modulation of downstream signaling pathways $[18,20,21,52]$. Studies suggest that the activation of ERKs and p38 in various cancer cells lead to aberrant cell proliferation [53]. Consistent with the existing data, activation of SSTR2 or ORs alone or in combination inhibit ERK1/2 in MCF-7 and T47D cells more than the MDA-MB231 cells [28]. Interestingly, p38 mediated anti-apoptotic effects typically seen in breast cancer are remarkably diminished in MDAMB231 and T47D cells upon activation of SSTR2 and ORs. Surprisingly, T47D and MCF-7 cells are ER + ve, but the cellular response to SSTR2/OR activation and inhibition of p38 was pronounced in T47D cells. Although such discrepancy in inhibition of p38 may be attributed due to the changes in other isoforms of p38 in addition to the difference in the origin of these cells; MCF-7 (adenocarcinoma) and T47D (ductal carcinoma). However, the intensity of expression levels of ER in these cells cannot be avoided from the discussion and future studies are warranted in this direction. Moreover results described here are consistent with the previous studies showing an enhanced pro-apoptotic effect in MCF-7 cells over-expressing SSTR2 [16].

PI3K/AKT hyper-phosphorylation, uncontrolled breast cancer progression and resistance to hormonal therapy is well established $[48,54]$. In all three tumor cell lines, the status of phosphorylated PI3K/AKT was not significantly different from the control. Moreover, this blockade of PI3K/AKT specifically in MCF-7 and T47D cells was accompanied by an increased expression of tumor suppressor PTEN supporting the notion that loss of PTEN is due to PI3K/AKT activation $[48,49]$. Notably, the activation of PI3K/AKT induced ER $\alpha$ expression in MCF-7 cells and spared them from tamoxifen mediated apoptosis [54]. This suggests that enhanced PTEN expression, predominantly in ER + ve MCF-7 and T47D cells as described here may alleviate TAM resistance. The activation of PI3K/AKT has also been shown to down regulate p53 induced apoptosis in breast cancer [55]. Previous reports suggested that in MCF-7 cells with over-expression of ErbB2 significantly activate PI3K and decreased the expression of p53, however, this effect was reversed upon blocking PI3K pathway [56]. Taken into consideration, enhanced expression of p53 and comparable activation of PI3K/AKT to control also highlight novel function of SSTR2/ORs in breast cancer cells.

Given the receptor dependent role, SSTR2 and ORs regulating the MAPK and PI3K/AKT pathways in breast cancer cells is an indication of inhibition of EGFR functions. This speculation is supported by aggressive tumor proliferation in breast cancer displaying over-expression and hyper-phosphorylation of EGFR [24,51,57]. An inverse relationship between EGFR and ER has been established. Moreover, the absence of ER expression in human breast cancer cell lines including MDA-MB231 is associated with higher levels of functional EGFR protein and mRNA [58]. In parallel to previous studies, our data revealed complete blockade of EGFR phosphorylation upon activation of SSTR2 and ORs in MDAMB231 and T47D cells [59,60]. Conversely, in MCF-7 cells, EGFR phosphorylation was lower than the control suggesting that endogenous EGFR phosphorylation is relatively higher in comparison to other cancer cells. We anticipate that the SSTR2/ORs mediated inhibition of EGFR phosphorylation possibly arrest the downstream MAPK and PI3K/AKT signaling thereby inducing the expression of tumor suppressor PTEN and p53. This supposition is further supported by our recent studies showing the inhibition of EGFR phosphorylation by activation of SSTR1 or SSTR5 leading to the pronounced inhibition of cell proliferating signals in HEK-293 cells $[20,21]$. Moreover, the physiological response of tumor cells upon activation of SSTR2/ORs parallel the changes seen in downstream signaling. FACs analysis revealed higher necrotic cell population ( $>25 \%$ ) in MCF-7 and T47D cells than MDA-MB231 cells. The early apoptosis increased upon specific treatment, however, was limited to $<5 \%$. Consistent with previous studies, our observations suggest a much pronounced cytotoxic role of SSTR2 and ORs in breast cancer cells as described previously [16]. These observations warrant concentration and time dependent effect of SSTR2/OR agonist on apoptosis and necrosis and further studies are in progress in this direction.

Targeting EGFR hyperactivity and PI3K/AKT pathways have been the therapeutic approach for the treatment of breast cancer. SSTR2 agonists have been clinically used for the treatment of acromegaly and pancreatic tumors, whereas ORs are emerging new members of GPCR family for their anti-proliferative role in various tumors. Therefore, targeting SSTR2 and specific ORs could possibly be a better therapeutic approach in breast cancer treatment. In addition to the anti-proliferative role, the analgesic role of ORs in the treatment of breast cancer cannot be neglected since patients undergoing chemotherapy are known to experience pain. Previously, SST analogs have been proven to be effective in pain relief in 
cases where opioids therapy failed [61]. It would be worth investigating the dual role of ORs as a tumor suppressor and analgesic agent in the treatment of breast cancer in synergism with SSTR subtypes. Our observations uncovered the new role of SSTR2 and ORs in combination in regulating the key tumor promoting signals in breast cancer cells. To determine whether such effect is partly due to direct functional interaction between these receptors further studies are in progress in this direction. Taken together, results presented in this study in part may be due the presence and expression intensity of ER. Furthermore, additional studies are essential to support whether knocking down ER in MCF-7 and T47D and transient expression of ER in MDA-MB231 cells display comparable changes. In conclusion, this is the first comprehensive study unveiling the molecular mechanisms of SSTR2/ORs mediated anti-proliferative signaling with novel therapeutic implications in breast cancer treatment.

\section{Competing interests}

The authors declare that they have no competing interests.

\section{Authors' contributions}

GK and UK conceived, designed and wrote the manuscript. GK performed experiments and analyzed the data. PSR performed microscopy and YL performed western blot. All authors read and approved the manuscript.

\section{Acknowledgements}

This work was supported by Canadian Institute of Health Research Grant (MOP 10268 and MOP 74465), grant from Canadian Breast Cancer Foundation BC/Yukon and NSERC to UK. UK is a Senior Scholar of Michael Smith Foundation for Health Research.

Received: 13 June 2013 Accepted: 23 August 2013

Published: 23 September 2013

\section{References}

1. Ben-Shlomo A, Melmed S: Somatostatin agonists for treatment of acromegaly. Mol Cell Endocrinol 2008, 286(1-2):192-198.

2. Buscail L, Esteve J, Saint-Laurent N, Bertrand V, Reisine T, O'Carroll A, Bell Gl, Schally AV, Vaysse N, Susini C: Inhibition of cell proliferation by the somatostatin analogue RC-160 is mediated by somatostatin receptor subtypes SSTR2 and SSTR5 through different mechanisms. Proc Nat Acad Sci 1995, 92(5):1580-1584.

3. Buscail L, Vernejoul F, Faure P, Torrisani J, Susini C: Regulation of cell proliferation by somatostatin. Ann Endocrinol (Paris) 2002, 63(2 Pt 3):2S13-12S18.

4. Kumar U, Grigorakis SI, Watt HL, Sasi R, Snell L, Watson P, Chaudhari S: Somatostatin receptors in primary human breast cancer: quantitative analysis of mRNA for subtypes 1-5 and correlation with receptor protein expression and tumor pathology. Breast Cancer Res Treat 2005, 92(2):175-186.

5. Prevost G, Hosford D, Thomas F: Receptors for somatostatin and somatostatin analogues in human breast tumors. Ann N Y Acad Sci 1994 733:147-154.

6. Murray RD, Kim K, Ren SG, Chelly M, Umehara Y, Melmed S: Central and peripheral actions of somatostatin on the growth hormone-IGF-I axis. J Clin Invest 2004, 114(3):349-356.

7. Boccardo F, Amoroso D: Management of breast cancer: is there a role for somatostatin and its analogs? Chemotherapy 2001, 47(Suppl. 2):62-77.

8. Barrie R, Woltering EA, Hajarizadeh H, Mueller C, Ure T, Fletcher WS: Inhibition of angiogenesis by somatostatin and somatostatin-like compounds is structurally dependent. J Surg Res 1993, 55(4):446-450.

9. Florio T, Morini M, Villa V, Arena S, Corsaro A, Thellung S, Culler MD, Pfeffer U, Noonan DM, Schettini G, et al: Somatostatin inhibits tumor angiogenesis and growth via somatostatin receptor-3-mediated regulation of endothelial nitric oxide synthase and mitogen-activated protein kinase activities. Endocrinology 2003, 144(4):1574-1584.

10. Florio T, Thellung S, Arena S, Corsaro A, Spaziante R, Gussoni G, Acuto G, Giusti M, Giordano G, Schettini G: Somatostatin and its analog lanreotide inhibit the proliferation of dispersed human non-functioning pituitary adenoma cells in vitro. Eur J Endocrinol 1999, 141(4):396-408.

11. Liu AMF, Wong YH: Activation of nuclear factor l̂० $\mathrm{B}$ by somatostatin type 2 receptor in pancreatic acinar AR42J cells involves Gl \pm 14 and multiple signaling components. J Biol Chem 2005, 280(41):34617-34625.

12. Reubi JC, Waser B, Foekens JA, Klijn JGM, Lamberts SWJ, Laissue J: Somatostatin receptor incidence and distribution in breast cancer using receptor autoradiography: relationship to egf receptors. Intnl J Can 1990, 46(3):416-420

13. Watt HL, Kharmate GD, Kumar U: Somatostatin receptors 1 and 5 heterodimerize with epidermal growth factor receptor: agonist-dependent modulation of the downstream MAPK signalling pathway in breast cancer cells. Cell Signal 2009, 21(3):428-439.

14. Vikic-Topic S, Raisch KP, Kvols LK, Vuk-Pavlovic S: Expression of somatostatin receptor subtypes in breast carcinoma, carcinoid tumor, and renal cell carcinoma. J Clin Endocrinol Metab 1995, 80(10):2974-2979.

15. Pfeiffer M, Koch $T$, Schroder $H$, Laugsch M, Hollt V, Schulz S: Heterodimerization of somatostatin and opioid receptors crossmodulates phosphorylation, internalization, and desensitization. J Biol Chem 2002, 277(22):19762-19772

16. He Y, Yuan X-m, Lei P, Wu S, Xing W, Lan X-I, Zhu H-f, Huang T, Wang G-b, An $\mathrm{R}$, et al: The antiproliferative effects of somatostatin receptor subtype 2 in breast cancer cells. Acta Pharmacol Sin 2009, 30(7):1053-1059.

17. Bousquet C, Guillermet-Guibert J, Saint-Laurent N, Archer-Lahlou E, Lopez F, Fanjul M, Ferrand A, Fourmy D, Pichereaux C, Monsarrat B, et al: Direct binding of p85 to sst2 somatostatin receptor reveals a novel mechanism for inhibiting PI3K pathway. Embo J 2006, 25(17):3943-3954.

18. Grant M, Kumar U: The role of G-proteins in the dimerisation of human somatostatin receptor types 2 and 5. Regul Pept 2009, 159(1-3):3-8.

19. Reardon DB, Dent $P$, Wood SL, Kong T, Sturgill TW: Activation in vitro of somatostatin receptor subtypes 2,3 , or 4 stimulates protein tyrosine phosphatase activity in membranes from transfected Ras-transformed NIH 3 T3 cells: coexpression with catalytically inactive SHP-2 blocks responsiveness. Mol Endocrinol 1997, 11(8):1062-1069.

20. Kharmate G, Rajput PS, Watt HL, Somvanshi RK, Chaudhari N, Qiu X, Kumar U: Role of somatostatin receptor 1 and 5 on epidermal growth factor receptor mediated signaling. Biochim Biophys Acta 2011, 1813(6):1172-1189.

21. Kharmate G, Rajput PS, Watt HL, Somvanshi RK, Chaudhari N, Qiu X, Kumar U: Dissociation of epidermal growth factor receptor and ErbB2 heterodimers in the presence of somatostatin receptor 5 modulate signaling pathways. Endocrinology 2011, 152(3):931-945.

22. Foekens JA, Portengen $\mathrm{H}$, van Putten WL, Trapman A, Reubi JC Alexieva-Figusch J, Klijn JGM: Prognostic value of receptors for insulin-like growth factor 1, somatostatin, and epidermal growth factor in human breast cancer. Cancer Res 1989, 49:7002-7009.

23. Alroy I, Yarden Y: The ErbB signaling network in embryogenesis and oncogenesis: signal diversification through combinatorial ligandreceptor interactions. FEBS Lett 1997, 410(1):83-86.

24. Bacus SS, Gudkov AV, Esteva FJ, Yarden Y: Expression of erbB receptors and their ligands in breast cancer: implications to biological behavior and therapeutic response. Breast Dis 2000, 11:63-75.

25. Hatzoglou A, Ouafik LH, Bakogeorgou E, Thermos K, Castanas E: Morphine cross-reacts with somatostatin receptor SSTR2 in the T47D human breast cancer cell line and decreases cell growth. Cancer Res 1995, 55(23):5632-5636

26. Reisine T, Bell Gl: Molecular biology of opioid receptors. Trends Neurosci 1993, 16(12):506-510.

27. Panagiotou S, Bakogeorgou E, Papakonstanti E, Hatzoglou A, Wallet F, Dussert C, Stournaras C, Martin P-M, Castanas E: Opioid agonists modify breast cancer cell proliferation by blocking cells to the G2/M phase of the cycle: involvement of cytoskeletal elements. J Cell Biochem 1999, 73(2):204-211

28. Persson Al, Thorlin T, Bull C, Zarnegar P, Ekman R, Terenius L, Eriksson PS: $\mathrm{Mu}$ - and delta-opioid receptor antagonists decrease proliferation and increase neurogenesis in cultures of rat adult hippocampal progenitors. Eur J Neurosci 2003, 17(6):1159-1172. 
29. Zagon IS, McLaughlin PJ, Goodman SR, Rhodes RE: Opioid receptors and endogenous opioids in diverse human and animal cancers. J Natl Cancer Inst 1987, 79(5):1059-1065.

30. Scopsi L, Balslev E, Brunner N, Poulsen HS, Andersen J, Rank F, Larsson LI: Immunoreactive opioid peptides in human breast cancer. Am J Pathol 1989, 134(2):473-479.

31. Hatzoglou A, Bakogeorgou E, Castanas E: The antiproliferative effect of opioid receptor agonists on the T47D human breast cancer cell line, is partially mediated through opioid receptors. Eur J Pharmacol 1996, 296(2):199-207.

32. Maneckjee R, Biswas $R$, Vonderhaar BK: Binding of opioids to human MCF-7 breast cancer cells and their effects on growth. Cancer Res 1990, 50(8):2234-2238.

33. Devi LA: Heterodimerization of G-protein-coupled receptors: pharmacology, signaling and trafficking. Trends Pharmaco/ Sci 2001, 22(10):532-537.

34. Rocheville M, Lange DC, Kumar U, Patel SC, Patel RC, Patel YC: Receptors for dopamine and somatostatin: formation of hetero-oligomers with enhanced functional activity. Science 2000, 288(5463):154-157.

35. Baragli A, Alturaihi H, Watt HL, Abdallah A, Kumar U: Heterooligomerization of human dopamine receptor 2 and somatostatin receptor 2 : co-immunoprecipitation and fluorescence resonance energy transfer analysis. Cell Signal 2007, 19(11):2304-2316.

36. Grant M, Collier B, Kumar U: Agonist-dependent dissociation of human somatostatin receptor 2 dimers: a role in receptor trafficking. $J$ Biol Chem 2004, 279(35):36179-36183.

37. Patel RC, Kumar U, Lamb DC, Eid JS, Rocheville M, Grant M, Rani A, Hazlett T, Patel SC, Gratton E, et al: Ligand binding to somatostatin receptors induces receptor-specific oligomer formation in live cells. Proc Natl Acad Sci USA 2002, 99(5):3294-3299.

38. Jaquet P, Gunz G, Saveanu A, Dufour H, Taylor J, Dong J, Kim S, Moreau JP, Enjalbert A, Culler MD: Efficacy of chimeric molecules directed towards multiple somatostatin and dopamine receptors on inhibition of $\mathrm{GH}$ and prolactin secretion from $\mathrm{GH}$-secreting pituitary adenomas classified as partially responsive to somatostatin analog therapy. Eur J Endocrinol 2005, 153(1):135-141.

39. Saveanu A, Gunz G, Guillen S, Dufour H, Culler MD, Jaquet P: Somatostatin and dopamine-somatostatin multiple ligands directed towards somatostatin and dopamine receptors in pituitary adenomas. Neuroendocrinology 2006, 83(3-4):258-263.

40. Saveanu A, Lavaque E, Gunz G, Barlier A, Kim S, Taylor JE, Culler MD, Enjalbert $A$, Jaquet $P$ : Demonstration of enhanced potency of a chimeric somatostatin-dopamine molecule, BIM-23A387, in suppressing growth hormone and prolactin secretion from human pituitary Somatotroph adenoma cells. J Clin Endocrinol Metab 2002, 87(12):5545-5552.

41. Rivera JA, Alturaihi $H$, Kumar U: Differential regulation of somatostatin receptors 1 and 2 mRNA and protein expression by tamoxifen and estradiol in breast cancer cells. J Carcinog 2005, 4(1):10.

42. Xu Y, Berelowitz M, Bruno JF: Dexamethasone regulates somatostatin receptor subtype messenger ribonucleic acid expression in rat pituitary GH4C1 cells. Endocrinology 1995, 136(11):5070-5075.

43. Xu Y, Song J, Berelowitz M, Bruno JF: Estrogen regulates somatostatin receptor subtype 2 messenger ribonucleic acid expression in human breast cancer cells. Endocrinology 1996, 137(12):5634-5640.

44. Kumar U: Expression of somatostatin receptor subtypes (SSTR1-5) in alzheimer's disease brain: an immunohistochemical analysis. Neuroscience 2005, 134:525-538.

45. Kumar U: Colocalization of somatostatin receptor subtypes (SSTR1-5) with somatostatin, NADPH-diaphorase (NADPH-d), and tyrosine hydroxylase in the rat hypothalamus. J Comp Neurol 2007, 504(2):185-205.

46. Enslen H, Brancho DM, Davis RJ: Molecular determinants that mediate selective activation of p38 MAP kinase isoforms. Embo J 2000, 19(6):1301-1311.

47. Zarubin T, Han J: Activation and signaling of the p38 MAP kinase pathway. Cell Res 2005, 15(1):11-18.

48. Berns K, Horlings HM, Hennessy BT, Madiredjo M, Hijmans EM, Beelen K, Linn SC, Gonzalez-Angulo AM, Stemke-Hale K, Hauptmann M, et al: A functional genetic approach identifies the PI3K pathway as a major determinant of trastuzumab resistance in breast cancer. Cancer Cell 2007, 12(4):395-402

49. Esteva FJ, Guo H, Zhang S, Santa-Maria C, Stone S, Lanchbury JS, Sahin AA, Hortobagyi GN, Yu D: PTEN, PIK3CA, p-AKT, and p-p70S6K status: association with trastuzumab response and survival in patients with HER2-positive metastatic breast cancer. Am J Pathol 2010, 177(4):1647-1656.

50. López-Knowles E, OToole SA, McNeil CM, Millar EKA, Qiu MR, Crea P, Daly RJ, Musgrove EA, Sutherland RL: PI3K pathway activation in breast cancer is associated with the basal-like phenotype and cancer-specific mortality. Int J Cancer 2009, 126(5):1121-1131.

51. Kallergi G, Agelaki S, Kalykaki A, Stournaras C, Mavroudis D, Georgoulias V: Phosphorylated EGFR and PI3K/Akt signaling kinases are expressed in circulating tumor cells of breast cancer patients. Br Cancer Res 2008, 10(5):R80

52. Gomes I, Jordan BA, Gupta A, Rios C, Trapaidze N, Devi LA: G protein coupled receptor dimerization: implications in modulating receptor function. J Mol Med 2001, 79(5-6):226-242.

53. Nebreda AR, Porras A: p38 MAP kinases: beyond the stress response. Trends Biochem Sci 2000, 25(6):257-260.

54. Campbell RA, Bhat-Nakshatri P, Patel NM, Constantinidou D, Ali S, Nakshatri H: Phosphatidylinositol 3-kinase/AKT-mediated activation of estrogen receptor Ît. J Biol Chem 2001, 276(13):9817-9824.

55. Sabbatini P, McCormick F: Phosphoinositide $3-\mathrm{OH}$ kinase (PI3K) and PKB/ Akt delay the onset of p53-mediated, transcriptionally dependent apoptosis. J Biol Chem 1999, 274(34):24263-24269.

56. Zheng L, Ren JQ, Li H, Kong ZL, Zhu HG: Downregulation of wild-type p53 protein by HER-2/neu mediated PI3K pathway activation in human breast cancer cells: its effect on cell proliferation and implication for therapy. Cell Res 2004, 14(6):497-506.

57. Gan HK, Walker F, Burgess AW, Rigopoulos A, Scott AM, Johns TG: The epidermal growth factor receptor (EGFR) tyrosine kinase inhibitor AG1478 increases the formation of inactive Untethered EGFR dimers. J Biol Chem 2007, 282(5):2840-2850.

58. Davidson NE, Gelmann EP, Lippman ME, Dickson RB: Epidermal growth factor receptor gene expression in estrogen receptor-positive and negative human breast cancer cell lines. Mol Endocrinol 1987, 1(3):216-223.

59. Lichtner RB, Menrad A, Sommer A, Klar U, Schneider MR: Signaling-inactive epidermal growth factor receptor/ligand complexes in intact carcinoma cells by quinazoline tyrosine kinase inhibitors. Cancer Res 2001, 61(15):5790-5795.

60. Narayan M, Wilken JA, Harris LN, Baron AT, Kimbler KD, Maihle NJ: Trastuzumab-induced HER reprogramming in "resistant" breast carcinoma cells. Cancer Res 2009, 69(6):2191-2194.

61. Williams G, Ball J, Bloom S, Joplin GF: Improvement in headache associated with prolactinoma during treatment with a somatostatin analogue: an "N of 1" study. N Engl J Med 1986, 315(18):1166-1167.

\section{doi:10.1186/1475-2867-13-93}

Cite this article as: Kharmate et al:: Inhibition of tumor promoting signals by activation of SSTR2 and opioid receptors in human breast cancer cells. Cancer Cell International 2013 13:93.

\section{Submit your next manuscript to BioMed Central and take full advantage of:}

- Convenient online submission

- Thorough peer review

- No space constraints or color figure charges

- Immediate publication on acceptance

- Inclusion in PubMed, CAS, Scopus and Google Scholar

- Research which is freely available for redistribution 